\title{
Effectiveness of yoga combined with back school program on anxiety, kinesiophobia and pain in people with non-specific chronic low back pain: a prospective randomized trial
}

\author{
Andrea De Giorgio',2,3 \\ Johnny Padulo1,2,3 \\ Goran Kuvačić2,3 \\ 1 eCampus University, Faculty of Psychology, \\ Novedrate (CO), Italy \\ 2 University of Split, Faculty of Kinesiology, \\ Split, Croatia \\ ${ }^{3}$ University of Split, Sport Performance Laboratory, \\ Split, Croatia
}

Corresponding author:

Andrea De Giorgio

Faculty of Psychology

eCampus University

Via Isimbardi 10

22060 Novedrate (CO), Italy

E-mail: andrea.degiorgio@uniecampus.it

\section{Summary}

Introduction: The aim of this study was to investigate the efficacy of Yoga combined with Back school program intervention compared to Yoga program only in order to evaluate anxiety, kinesiophobia, back pain disability and quality of life in people affected by non-specific chronic low back pain.

Methods: In this randomized controlled trial, 70 participants (age $37.97 \pm 5.54$ years) with non-specific chronic low back pain were randomized to undergone experimental Yoga combined with Back school group (35 subjects; Intervention) or Hatha Yoga program group (35 subjects, Control) respectively. The intervention consisted of Yoga exercise sessions with Back school meetings, two times per week for 8 weeks. We investigate the effectiveness of these interventions through some psychological factors: anxiety (Hamilton anxiety scale HAM-A), kinesiophobia (Tampa Scale for Kinesiophobia TSK), back pain disability (Roland Morris Disabilities RMQ), and quality of life (36 Item Short Form Survey SF-36).

Results: We found significant decrease in mean scores of all psychological variables (Anxiety $F_{2,68}=53.504, p<0.001$; Kinesiophobia $F_{2,68}=52.244$, $p<0.001$; Disability $F_{2,68}=128.343, p<0.001$ ) and increase in health-related quality of life sub-scales (Bodily pain $\mathrm{F}_{1,34}=20.907, \mathrm{p}<0.001$; General mental health $F_{1,34}=7.319, p=0.011$; General health per- ceptions $F_{1,34}=7.879, p=0.008$ ) in Intervention group. Both groups were significantly different in all psychological variables and three sub-scales relate to the quality life (Physical functioning, Bodily pain, and General health perceptions) at the end of 8 and 12 training interventions weeks.

Conclusions: This study demonstrated effectiveness of Yoga combined with Back school intervention in people affected by $\mathrm{nCLBP}$ with lowering Anxiety, Kinesiophobia and Disability together with improving the quality of life.

Level of evidence: Ib.

KEY WORDS: exercise physiology, longitudinal study, public health, training and testing.

\section{Introduction}

Low back pain is recognized as one of the leading cause of disability worldwide ${ }^{1}$. In USA musculoskeletal disorders such as chronic low back pain (CLBP) are the most common reasons of inactivity in general population under 45 years and the second most important cause for medical treatment or visit to the physician's ${ }^{2}$. In Italy, prevalence of CLBP is about $5.91 \%$, or 3.5 million people ${ }^{3}$. Literature describes the non-specific chronic low back pain (nCLBP) as lowback pain persisting for at least 3 months. This type of pain is severe, and usually initial treatments do not have positive effects. For these reasons it requires a thorough medical treatment to highlight the exact cause of the pain ${ }^{4}$. Under nCLBP many common diagnoses can be grouped such as muscle spasm, mechanical low back pain, lumbago, myofascial syndrome, etc. ${ }^{5}$

Moreover, nCLBP and other chronic musculoskeletal disorders can lead to limitation for social and working activity; people suffering these disorders have other associated problems such as depression ${ }^{6}$, anxiety ${ }^{7}$, disability $^{2}$ and kinesiophobia ${ }^{8}$ which, in turn, lead to a reduced quality of life $(\mathrm{Q} O L)^{9}$. In particular, pain is closely related to fear of movement (i.e. kinesiophobia), which lead to prolonging movement difficulty ${ }^{10}$. In the past years it has been proposed the so-called fear-avoidance model, which explain how pain induces an altered self-perception, which results in an intensive fear of movement ${ }^{11}$. Scientific literature presents plenty of studies and guidelines to improve the QoL in patients affected by nCLBP, but there is not a 
Effectiveness of yoga combined with back school program on anxiety, kinesiophobia and pain in people with non-specific chronic low back pain: a prospective randomized trial

general agreement on their efficiency5,12-14. Yoga practice has proved to be a useful tool to treat nCLBP and associated psychological problems ${ }^{15}$. Recently, Saper et al. ${ }^{16}$ published an article in which they demonstrated the efficiency of yoga, physical therapy and education in nCLBP treatment, concluding that yoga is very efficient and non-inferior to physical treatment for addressing this pathology. Wieland et al. ${ }^{17}$ in an interesting review discuss that yoga compared to non-exercise controls is able to reduce low-back pain symptoms with low- to moderate-certainty evidence. Moreover, the same Authors in their conclusion affirm: "It is uncertain whether there is any difference between yoga and other exercise for backrelated function or pain, or whether yoga added to exercise is more effective than exercise alone".

Developed in Scandinavian country by ZachrissonForsell since 1969, the so-called "Back school" is the most used exercise program in the world for managing $\mathrm{nCLBP}^{18}$. Besides exercises, the Back school program consists of an educational and skill acquisition program supervised by healthcare professionals and motor science experts, including I) informing patient about spinal anatomy and biomechanics; II) the correct use of the spine even with respect to all daily activities; III) exercise programs for spine function reeducation and pain reduction ${ }^{18,19}$.

Heymans et al. ${ }^{12}$ evaluated the effectiveness of Back School through nineteen randomized clinical trials with 3584 patients. Authors conclude that there is a moderate evidence of efficacy in short and medium term in nCLBP using this approach, but they also highlight that several trials were methodologically unsatisfactory. Moreover, a more intense treatment as modification of the Scandinavian Back School seems to have better results ${ }^{12}$ (i.e., from three to five perweek stay in a specialized center). This Back school treatment is characterized by brief education and includes meetings with healthcare professionals and the distribution of educational booklets to encourage active self-management for $\mathrm{nCLBP}^{13}$.

However, at the best of our knowledge, both interventions, i.e., Yoga combined with Back school, were not performed together, despite other particular interventions were proposed, such as, for example, Yilmaz et al. ${ }^{8}$ who performed integrated virtual walking physiotherapy in order to manage low-back pain.

The aim of this study was to investigate the efficacy of Yoga combined with Back school versus Yoga intervention only in order to evaluate the psychological factors and QoL in people affected by nCLBP.

\section{Materials and methods}

\section{Subjects}

Subjects were recruited by general practitioner who knew their clinical history and diagnosed nCLBP. The general practitioner, specialized in physiatry, has followed all his patients along the research and regularly visited the patients (every 10 days) so as to moni- tor the trend of CLBP and, in case of aggravation, to withdraw the patient from the research. All subjects were investigated for demographic and clinical characteristics (Tab. I). Inclusion criteria were: (1) pervasive nCLBP, (2) adult age (18 years or older), (3) no simultaneous presence of two chronic diseases or conditions comorbidity. Exclusion criteria were: (1) acute low back pain (included recent thoracic-lumbar trauma), (2) specific causes of low back pain (lumbar stenosis, disc hernia, spinal deformity, fracture, spondylosis), (3) current or preexisting neurologic, oncologic or psychiatric conditions, such as dementia, Parkinson's disease, congenital central nervous system malformations, multiple sclerosis, tumors, schizophrenia or head trauma. Patients with recent cerebro-vascular accidents and myocardial infarctions or obesity were also excluded. Randomized controlled trial is presented according to CONSORT guidelines (Fig. 1). Of the 73 subjects assessed, 70 met the aforementioned criteria and consented to be enrolled in this prospective randomized study. A total of 70 subjects completed the randomized trial of which 38 were men and 32 females with average of 37.97 years $(S D=5.54)$. $68.5 \%$ of them where employed and had High School or University diploma (95.7\%). Pharmacological therapy for CLBP had 40\% of subjects with both analgesic and muscle relaxant drugs $(21.4 \%)$ as relief of for pain. Physiatric and physiotherapic therapy attended $41.4 \%$ subjects. There were no comorbidities among subjects in this research.

After the enrollment, we then randomized the subjects into two groups: Yoga intervention only ( $\mathrm{Y}$; considered also as Control group) and Yoga + Back School intervention (Y\&B; considered also as Intervention group). All people participate to 8-weeks $Y$ or $Y \& B$ program and were tested with questionnaire at the end and after 12-weeks from the beginning of program (i.e., one month after the end). All procedures were approved by Local Ethics Committee and were in accordance with MLTJ guidelines ${ }^{20}$.

\section{Description of the intervention}

\section{Yoga (Control group)}

The yoga exercise program, led by a certified yoga instructor, was 8-weeks long. We used a modern Hatha Yoga which usually combines elements of postural positioning, breathing, concentration, and meditation. The yoga instructor provides guidance for correct postures, breathing and focus, encouraging positive self-images. Each participant has yoga activities twice-a-week in the fitness center. Each session takes 60-90 minutes and usually comprised a 10-min breathing exercise, 45-min yoga pose practice; 15min supine meditation/relaxation. In this study, we performed the five-basic yoga poses: cat-cow, child's pose, downward dog, plank, and cobra. Cat-cow pose stretches the abdominal muscles, neck and back, and maintains the flexibility of the spine; this pose is especially helpful for people with stiff backs. Balasana 


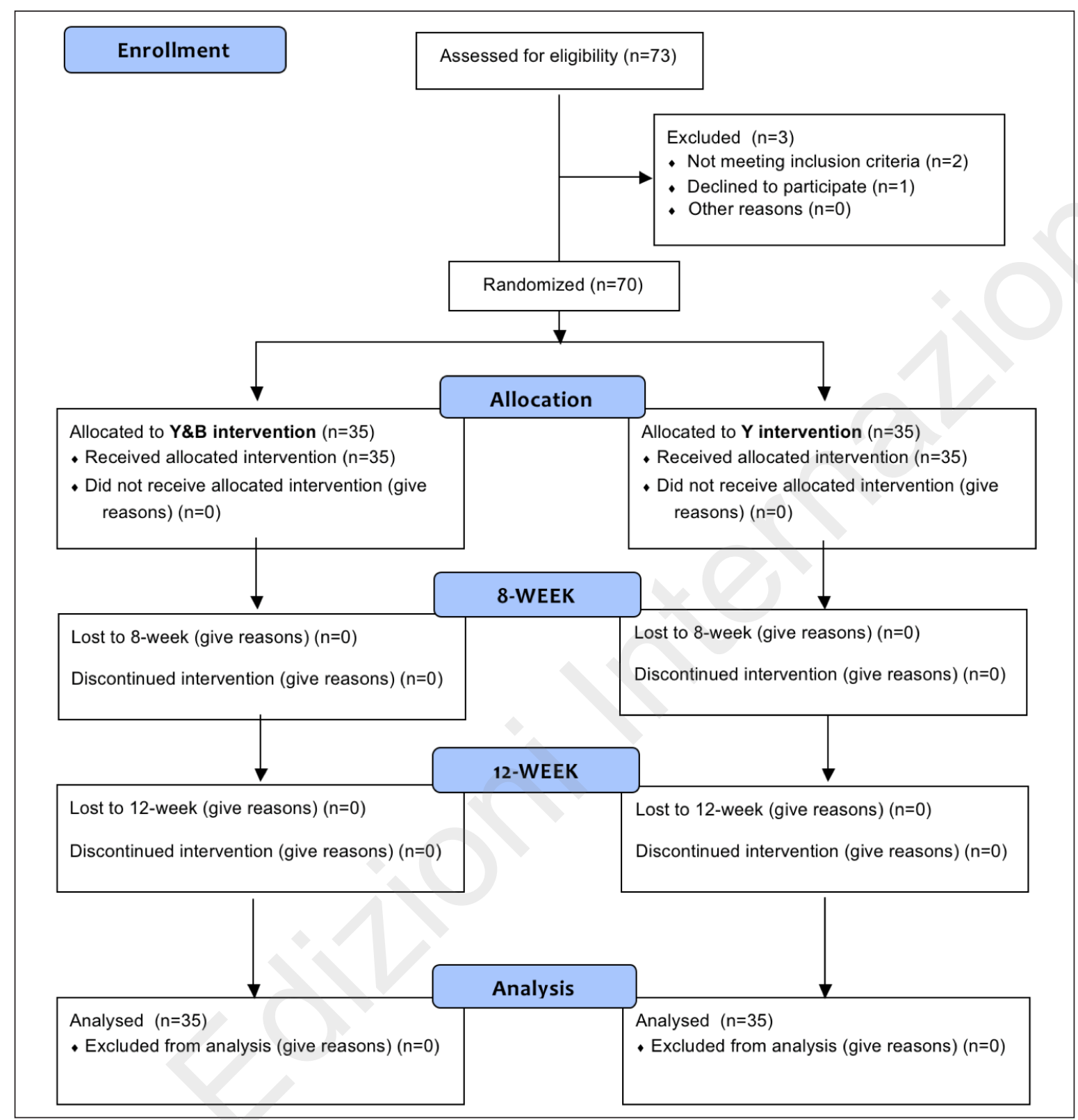

Figure 1. Flowchart depicting the procedure of the study. Y\&B, yoga combined with back pain treatment; $\mathrm{Y}$, Hatha yoga treatment.

(i.e., child's pose) stretches the lower back and hip from discomfort, helps to relieve stress, fatigue, gas, and bloating ${ }^{21}$. Adho Mukha Svanasana (i.e., downward dog pose) stretching the shoulders, hamstrings, calves, and chest while strengthens arms, shoulders, abdominal and quadriceps muscles, and ankles. Plank pose strengthens the arms, wrists, and spine. Bhujangasana (i.e., cobra pose) maintains the flexibility of the spine and stretches the chest and abdominal muscles, also improving poor posture and combats depression, lower back discomfort, and low energy. At the end of the session during supine meditation any meditative posture can be assumed with the eyes closed and the whole body relaxed. In particu- lar, the Savasana (i.e., dead body), is performed by lying down, face up with the arms and legs comfortably apart and palms facing upward, eyes closed, and the whole body consciously relaxed. These final postures help to relax the whole psycho-physiologic system.

\section{Yoga combined with Back School (Intervention group)}

Subjects participated in this 8 -weeks program (Y\&B) two times per week. The first meeting was Back School, the second Yoga, and so on (i.e., the third Back School meeting, fourth yoga, etc.). Back school consists of a physical exercises and educa- 
Effectiveness of yoga combined with back school program on anxiety, kinesiophobia and pain in people with non-specific chronic low back pain: a prospective randomized trial

tional program, therefore meetings were conducted by a person with master degree in Motor sciences with first and second level in Back School. His role in the intervention was administration in the stabilization phase of the pathology, strengthening the muscles and to provide useful information regarding the correct positions and posture of spine. Yoga encounters were performed by the same Yoga instructor and as already described in Yoga program paragraph. Back School meetings had the following characteristics. The sessions lasted an hour and each group was composed of a maximum of 10 subjects. The subjects could not attend the classes in which the subjects of the Yoga group were present. During the first meeting, the anatomy and biomechanics of the spine were described, as well as ergonomic positions to be taken during activities of daily living such as eating, dressing, bathing, grooming or other recreational situations like sport and gardening. Following this explanation, people tried to test some daily activities (e.g., raise weight, sit down) and correct wrong postures. Back School teacher also provided information on pain, how stress and anxiety can affect posture and how to handle stress. At the end of this meeting, the subjects were encouraged to pay more attention to the positions taken during daily activities and a pamphlet was delivered to them, summarizing what was described during this meeting. From the second Back School meeting, exercises were based on breathing education, self-stretching trunk muscles, erector spine reinforcement, abdominal reinforcement and postural exercises. Each session was performed on 70-minute related to the Back School comprised a 10-minute breathing exercise; 50' of Grounding and Palming at desk, correct use of spine at work, in leisure and rest, test of active and dynamic sitting, counterbalance movement for back pain, lumbar exercise, exercises for back pain and neck pain; 10' supine meditation/relaxation.

\section{Measures}

We evaluated the results in Anxiety, Kinesiophobia, Back pain disability and Quality of life using respectively Hamilton anxiety scale, Tampa Scale for Kinesiophobia, Roland Morris Disabilities and SF-36 questionnaire.

Anxiety: In order to test anxiety, the Hamilton anxiety rating scale (HAM-A) ${ }^{22}$ was used. This questionnaire developed in 1959 by Dr. Hamilton, is a well-validated and widely used for measuring the severity of a patient's anxiety. This scale probes 14 parameters and each item are scored on a 5-point scale, ranging from $0=$ not present to $4=$ severe. The total score ranges from 0 to 56 , where $<17$ indicates mild severity, 18-24 mild to moderate severity and $25-30$ moderate to severe.

Kinesiophobia: To evaluate the fear of movement the Tampa Scale Kinesiophobia Questionnaire (TSK) was used. The Italian version of TSK scale was developed by Monticone et al. ${ }^{23}$ and consists of 13 items scored on a four-point Likert scale from 0 to 4 (from "strongly disagree", 1 to "strongly agree "4), in order to identify the fear of movement. The scale is based on the model of fear-avoidance, fear of activity related to work, movement or relapse ${ }^{24}$. The English version, consisting of 17 items, the total cut-off of the questionnaire was established to 37 points and the measured margin of error was estimated as 3 points, then 34 and $40^{25}$. In the Italian version ${ }^{23}$ no cut-off was established, and it was recommended to consider the total score ${ }^{26}$. By carrying out a proportion between the cut-off established by Kori and collaborators, also according to the items belonging to Italian version and the acceptable margin of error, we set the cut-off to 31 . The questionnaire was administered for both groups the day in which the Yoga or Yoga and Back school program at beginning and after 8 and - 12-weeks.

Disability: In order to test disability, the Roland Morris Disability Questionnaire (RMQ) ${ }^{27}$ was used. This questionnaire was published for the first time by Roland and Morris in 1983. The Roland Morris Disability Questionnaire is scored by adding up the number of items checked by the patient in a questionnaire consisting of 24 items also in Italian version ${ }^{28}$. Total score starts from 0 and can reach 24 . Total score from 0 to 9 indicates low disability; from 10 to 13 indicates mid disability; up to 14 points indicate severe disability.

Health-related quality of life (HRQL): To evaluate the quality of life, the 36-Item Short Form Health Survey (SF-36) was used ${ }^{29}$. This questionnaire is the most common and well-validated tool to measure general HRQL. It is a self-reported tool which including eight domains, characterized by different item: physical functioning, role limitations: physical, bodily pain, social functioning, general mental health, role limitations: emotional, vitality, energy or fatigue and general health perceptions. Total score of each domain ranges from 0 to 100 , with higher scores indicating a better QoL.

\section{Statistical analysis}

Statistical power analysis was carried out to calculate sample size. Results showed that total sample size should be twenty-eight to achieve a statistical power of $80 \%$ for a small effect size detection $(d=0.25)$ when assessed by two-way repeated-measure analysis of variance (ANOVA) with a level of significance of $5 \%$. By obtained findings, we, therefore, recruited seventy subjects in the present study. To describe the subject's demographic data in each group, descriptive statistics (mean SD) were used. Two-way mixed design between-within $2 \times 3$ ANOVA (for psychological variables) and $2 \times 2$ ANOVA (for SF-36 questionnaire subscales) was used in order to detect differences between Control and Intervention group (factor Group) on changes in the psychological factors before, 8-week and 12-week after intervention (factor Time). For those variables in which interaction Time $\times$ Group was significant, one-way repeated measures ANOVA was performed to analyze the sim- 
ple main effect among three-time points in each group. With Levene test, assumption of sphericity was checked, and if violated, Greenhouse-Geiser corrections of degrees of freedom was applied. Analysis of covariance (ANCOVA) was applied on those variables in which time and group had interaction effects using the pretest data as the covariate to align the group differences at baseline of the initial measurement point with the aim of assessing the group differences at 8-week and 12-week time points of the study. For the multiple comparisons, Bonferroni correction was used if significant main effects were detected. The level of significantly was fixed to $p<0.05$. Statistical analyses were carried out using Statistica software version 13.0 (Dell Inc., Round Rock, TX USA).

\section{Results}

Results of $t$-test at baseline of the research showed significant differences in Anxiety $(\mathrm{t}=-2.498, \mathrm{p}=0.015)$ and General mental health $(t=2.097, p=0.040)$ between two groups. Intervention group had slightly higher scores of Anxiety ( $M=20.51, S D=2.66)$ in comparison with Control group $(M=19.26, S D=1.34)$. Also, in General mental health Control group had better scores than Intervention group (CON $M=67.71$, $\mathrm{SD}=9.8$; EXP $M=62.57, \mathrm{SD}=10.70$ ). In all remaining variables there was no significant differences at baseline of this research.

With applied two-way mixed design ANOVA, we found significant Time $\times$ Group interaction in seven variables (Tab. I): Anxiety $\left(F_{2,136}=11.160 ; p<0.001\right)$,

Table I. Results of two way repeated measures ANOVA - within/between subjects effects and interaction.

\begin{tabular}{|c|c|c|c|c|c|c|c|}
\hline \multirow{2}{*}{ Variable } & & \multicolumn{2}{|l|}{ Time } & \multicolumn{2}{|l|}{ Group } & \multicolumn{2}{|c|}{ TimexGroup } \\
\hline & & $F(p)$ & $\eta^{2}$ & $F(p)$ & $\eta 2$ & $F(p)$ & $\eta^{2}$ \\
\hline \multirow{3}{*}{$\begin{array}{l}\text { Physiological } \\
\text { factors }\end{array}$} & Anxiety & $44.107(0.000)$ & 0.393 & $\begin{array}{l}2.923 \\
(0.092)\end{array}$ & 0.041 & $\begin{array}{l}11.160 \\
(0.000)\end{array}$ & 0.141 \\
\hline & Kinesiophobia & $32.113(0.000)$ & 0.321 & $\begin{array}{l}41.708 \\
(0.000)\end{array}$ & 0.380 & $\begin{array}{l}17.254 \\
(0.000)\end{array}$ & 0.202 \\
\hline & Disability & $177.673(0.000)$ & 0.732 & $\begin{array}{l}3.502 \\
(0.066)\end{array}$ & 0.049 & $\begin{array}{l}33.669 \\
(0.000)\end{array}$ & 0.331 \\
\hline \multirow{8}{*}{$\begin{array}{l}\text { SF-36 } \\
\text { questionnaire } \\
\text { Subscales }\end{array}$} & Physical functioni & $0.821(0.368)$ & 0.012 & $\begin{array}{l}1.923 \\
(0.1 .69)\end{array}$ & 0.028 & $\begin{array}{l}6.513 \\
(0.013)\end{array}$ & 0.087 \\
\hline & Role limitations & $0.761(0.386)$ & 0.011 & $\begin{array}{l}1.384 \\
(0.244)\end{array}$ & 1.384 & $\begin{array}{l}1.190 \\
(0.279)\end{array}$ & 0.017 \\
\hline & Bodily pain & $9.772(0.003)$ & 0.125 & $\begin{array}{l}5.349 \\
(0.024)\end{array}$ & 0.073 & $\begin{array}{l}6.020 \\
(0.017)\end{array}$ & 0.081 \\
\hline & Social functioning & $1.892(0.174)$ & 0.027 & $\begin{array}{l}1.400 \\
(0.241)\end{array}$ & 0.020 & $\begin{array}{l}1.093 \\
(0.300)\end{array}$ & 0.016 \\
\hline & General mental health & $9.776(0.003)$ & 0.126 & $\begin{array}{l}0.098 \\
(0.755)\end{array}$ & 0.001 & $\begin{array}{l}4.289 \\
(0.042)\end{array}$ & 0.059 \\
\hline & $\begin{array}{l}\text { Role limitations due to } \\
\text { emotional problems }\end{array}$ & $1.931(0.169)$ & 0.028 & $\begin{array}{l}2.041 \\
(0.158)\end{array}$ & 0.029 & $\begin{array}{l}1.343 \\
(0.251)\end{array}$ & 0.019 \\
\hline & $\begin{array}{l}\text { Vitality, energy or } \\
\text { fatigue }\end{array}$ & $7.081(0.010)$ & 0.094 & $\begin{array}{l}0.000 \\
(0.982)\end{array}$ & 0.000 & $\begin{array}{l}0.323 \\
(0.572)\end{array}$ & 0.005 \\
\hline & $\begin{array}{l}\text { General health } \\
\text { perceptions }\end{array}$ & $2.637(0.109)$ & 0.037 & $\begin{array}{l}6.104 \\
(0.016)\end{array}$ & 0.082 & $\begin{array}{l}6.652 \\
(0.012)\end{array}$ & 0.089 \\
\hline
\end{tabular}

Legend: $F$, f test; $p$, significance; $\eta^{2}$, effect size. 
Effectiveness of yoga combined with back school program on anxiety, kinesiophobia and pain in people with non-specific chronic low back pain: a prospective randomized trial

Kinesiophobia $\left(F_{2,136}=17.254 ; p<0.001\right)$, Disability $\left(F_{2,136}=33.669 ; p<0.001\right)$, Physical functioning $\left(F_{1,68}=\right.$ $6.513 ; p=0.013)$, Bodily pain $\left(F_{1,68}=6.020 ; p=0.017\right)$, General mental health $\left(F_{1,68}=4.289 ; p=0.042\right)$ and General health perceptions $\left(F_{1,68}=6.652 ; p=0.012\right)$. Table II shows simple main effect of different time points in each group. In Intervention group we found significant decrease in mean scores of all psychological (Anxiety $\mathrm{F}_{2,68}=53.504, \mathrm{p}<0.001$; Kinesiophobia $F_{2,68}=52.244, p<0.001$; Disability $F_{2,68}=128.343$, $\mathrm{p}<0.001)$ and increase in health-related quality of life sub-scales (Bodily pain $F_{1,34}=20.907, p<0.001$; General mental health $\mathrm{F}_{1,34}=7.319, \mathrm{p}=0.011$; General health perceptions $F_{1,34}=7.879, p=0.008$ ), while in Control group there was significant decrease in mean scores only in Anxiety $\left(F_{2,68}=5.137, p=0.013\right)$ and Disability $\left(F_{2,68}=49.386, p<0.001\right)$.

Group differences are shown in Table III. By obtained results, it can be concluded that groups were significantly different in all psychological variables at the end of 8 and 12 week. Intervention group benefit more after the intervention, where mean scores are lower than in Control group. Also in subscales that assessed quality life, there was significant difference between observed groups in Physical functioning,
Bodily pain, and General health perceptions, but not in General mental health.

\section{Discussion}

We demonstrated that $Y \& B$ treatment was more effective compared to Hatha Yoga treatment to improve the QoL in people affected by nCLBP. Particularly, $Y \& B$ was useful to enhance psychological outcomes such as anxiety, kinesiophobia and QoL (in which is also included a subscale in regard to bodily pain) more than only Hatha yoga. At the best of our knowledge literature does never describe this combined treatment. The effectiveness of yoga treatments (Hatha, Nidra, etc.) to enhance psychological outcomes in depression ${ }^{30}$, in women with menstrual disorders $^{31}$, in reducing anxiety ${ }^{32}$, in glycemic control ${ }^{33}$, during cancer treatment ${ }^{34}$ and, of course, in nCLBP ${ }^{17}$, is widely documented.

Back school has proved useful in back pain management ${ }^{35}$ but recently Borys et al. ${ }^{36}$ have proved that this program could be also useful to ameliorate painrelated stress and associated psychological aspects. Literature also describe the so-called fear-avoidance

Table II. Results of one-way repeated measures ANOVA with Bonferroni post hoc test.

\begin{tabular}{|c|c|c|c|c|c|c|c|}
\hline \multirow[t]{2}{*}{ Variable } & & \multirow[t]{2}{*}{ Group } & \multirow{2}{*}{$\begin{array}{c}1 T \\
\text { Mean (SD) }\end{array}$} & \multirow{2}{*}{$\begin{array}{c}\text { 2T } \\
\text { Mean (SD) }\end{array}$} & \multirow{2}{*}{$\begin{array}{c}\text { 3T } \\
\text { Mean (SD) }\end{array}$} & \multirow[t]{2}{*}{$F(p), \varepsilon$} & \multirow[t]{2}{*}{ Post hoc ${ }^{a}$} \\
\hline & & & & & & & \\
\hline \multirow{6}{*}{$\begin{array}{l}\text { Psychological } \\
\text { factors }\end{array}$} & \multirow[t]{2}{*}{ Anxiety } & $\mathrm{CON}^{*}$ & $19.26(1.34)$ & $17.97(2.20)$ & 17.77 (2.38) & $\begin{array}{c}5.137(0.013) \\
0.840\end{array}$ & $1 \mathrm{~T}>2 \mathrm{~T} / 1 \mathrm{~T}>3 \mathrm{~T}$ \\
\hline & & EXP & $20.51(2.66)$ & $16.40(2.44)$ & $16.23(2.24)$ & $\begin{array}{c}53.504(0.000) \\
/-\end{array}$ & $1 \mathrm{~T}>2 \mathrm{~T} / 1 \mathrm{~T}>3 \mathrm{~T}$ \\
\hline & \multirow[t]{2}{*}{ Kinesiophobia } & $\mathrm{CON}^{*}$ & $34.63(4.43)$ & $33.06(2.80)$ & 33.89 (3.15) & $\begin{array}{c}2.083(0.143) \\
0.813\end{array}$ & NS \\
\hline & & EXP & $33.94(4.09)$ & $28.69(3.43)$ & $27.14(3.29)$ & $\begin{array}{c}52.244(0.000) \\
/-\end{array}$ & $1 \mathrm{~T}>2 \mathrm{~T} / 1 \mathrm{~T}>3 \mathrm{~T}$ \\
\hline & \multirow[t]{2}{*}{ Disability } & $\mathrm{CON}^{*}$ & $9.29(2.44)$ & $7.43(2.12)$ & $7.14(1.97)$ & $\begin{array}{c}49.386(0.000) \\
0.785\end{array}$ & $1 \mathrm{~T}>2 \mathrm{~T} / 1 \mathrm{~T}>3 \mathrm{~T}$ \\
\hline & & $\mathrm{EXP}^{*}$ & $10.46(2.52)$ & $5.86(2.18)$ & $4.94(1.92)$ & $\begin{array}{c}128.343 \\
(0.000), 0.623\end{array}$ & $\begin{array}{c}1 \mathrm{~T}>2 \mathrm{~T} / 2 \mathrm{~T}>3 \mathrm{~T} / \\
1 \mathrm{~T}>3 \mathrm{~T}\end{array}$ \\
\hline \multirow{8}{*}{$\begin{array}{l}\text { SF-36 } \\
\text { questionnaire } \\
\text { Subscales }\end{array}$} & \multirow{2}{*}{$\begin{array}{l}\text { Physical } \\
\text { functioning }\end{array}$} & CON & $80.45(17.89)$ & & $78.86(16.87)$ & $3.12(0.086)$ & NS \\
\hline & & EXP & $82.97(13.88)$ & & $86.32(13.03)$ & $3.819(0.059)$ & NS \\
\hline & \multirow[t]{2}{*}{ Bodily pain } & CON & $61.85(17.26)$ & & $63.71(18.20)$ & $0.176(0.678)$ & NS \\
\hline & & EXP & $62.14(15.49)$ & & $77.71(18.57)$ & $20.907(0.000)$ & $1 \mathrm{~T}<2 \mathrm{~T}$ \\
\hline & \multirow{2}{*}{$\begin{array}{l}\text { General mental } \\
\text { health }\end{array}$} & CON & $67.71(9.8)$ & \multirow{4}{*}{ l } & $69.94(8.53)$ & $3.608(0.066)$ & NS \\
\hline & & EXP & $62.57(10.70)$ & & $73.54(21.26)$ & $7.319(0.011)$ & $1 \mathrm{~T}<2 \mathrm{~T}$ \\
\hline & \multirow{2}{*}{$\begin{array}{l}\text { General health } \\
\text { perceptions }\end{array}$} & CON & $62.14(16.19)$ & & $60.71(14.35)$ & $0.519(0.476)$ & NS \\
\hline & & EXP & $66.14(13.23)$ & & $72.42(14.87)$ & $7.879(0.008)$ & $1 \mathrm{~T}<2 \mathrm{~T}$ \\
\hline
\end{tabular}

Legend: F, f test; $p$, significance; $\varepsilon$, Greenhouse-geiser epsilon; /, assumption of sphericity not violated; a, Bonferroni correction; NS, non significant; CON, control group; EXP, experimental group; 1T, pretesting (baseline); $2 \mathrm{~T}, 8$ week; $3 \mathrm{~T}$, 12 week. 
Table III. Results of ANCOVA - group differences.

\begin{tabular}{|c|c|c|c|c|c|c|}
\hline \multirow[b]{2}{*}{ Variable } & & \multirow[b]{2}{*}{ Group } & \multicolumn{2}{|l|}{$2 \mathrm{~T}$} & \multicolumn{2}{|l|}{ 3T } \\
\hline & & & $\begin{array}{l}\text { Adjusted } \\
\text { (Std.Err) }\end{array}$ & $M F(p)$ & $\begin{array}{l}\text { Adjusted } \\
\text { (Std.Err) }\end{array}$ & $M F(p)$ \\
\hline \multirow{6}{*}{$\begin{array}{l}\text { Psychological } \\
\text { factors }\end{array}$} & \multirow{2}{*}{ Anxiety } & CON & $18.16(0.39)$ & \multirow{2}{*}{$11.958(0.001)$} & $17.87(0.40)$ & \multirow{2}{*}{$9.041(0.004)$} \\
\hline & & EXP & $16.21(0.39)$ & & $16.13(0.40)$ & \\
\hline & Kinconnhobia & CON & $32.09(0.50)$ & \multirow{2}{*}{$34.640(0.000)$} & $33.83(0.53)$ & \multirow{2}{*}{$76.413(0.000)$} \\
\hline & nirseopriovia & EXP & $28.77(0.50)$ & & $27.20(0.53)$ & \\
\hline & \multirow{2}{*}{ Disability } & CON & $7.74(0.30)$ & \multirow{2}{*}{$26.583(0.000)$} & $7.39(0.28)$ & \multirow{2}{*}{$44.588(0.000)$} \\
\hline & & EXP & $5.55(0.30)$ & & $4.69(0.28)$ & \\
\hline \multirow{8}{*}{$\begin{array}{l}\text { SF-36 } \\
\text { questionnaire } \\
\text { Subscales }\end{array}$} & \multirow{2}{*}{ Physical functioning } & $\mathrm{CON}$ & & & $79.89(1.28)$ & \multirow{2}{*}{$8.812(0.004)$} \\
\hline & & EXP & & & $85.29(1.28)$ & \\
\hline & \multirow{2}{*}{ Bodily pain } & CON & & & $63.73(3.12)$ & \multirow{2}{*}{$10.047(0.002)$} \\
\hline & & EXP & & & $77.70(3.12)$ & \\
\hline & \multirow{2}{*}{$\begin{array}{l}\text { General mental } \\
\text { health }\end{array}$} & CON & 1 & & $69.26(2.76)$ & \multirow{2}{*}{$1.564(0.215)$} \\
\hline & & EXP & & & $74.22(2.76)$ & \\
\hline & \multirow{2}{*}{$\begin{array}{l}\text { General health } \\
\text { perceptions }\end{array}$} & CON & & & $61.98(1.93)$ & \multirow{2}{*}{$11.287(0.001)$} \\
\hline & & EXP & & & $71.17(1.93)$ & \\
\hline
\end{tabular}

Legend: F, f test; $p$, significance; CON, control group; EXP, Intervention group; 2T, 8 week; 3T, 12 week.

model, according to which people develop chronic musculoskeletal pain as a result of avoidant behavior based on fear ${ }^{11,37}$. Moreover, it has been demonstrated that patients with low back pain and depression had higher pain intensity, greater kinesiophobia and poorer QoL ${ }^{38}$. Therefore, people who develop chronic pain in the absence of other pathologies, as in the case of nCLBP, may be subject to avoiding some gestures, daily routines and/or sports activities in an effort to reduce the pain. This may lead to a dramatic decrease in the level of physical activities (i.e., disuse syndrome) that increases the perception of stiffness and pain of back. All these aspects can lead to a vicious circle that ends up with the QoL worsening ${ }^{39}$.

As aforementioned, pain is closely related to psychological factors, and it is no surprise that Yoga is able to reduce nCLBP, because it has proved useful in reducing anxiety ${ }^{31}$ and depression ${ }^{30}$ as well as it is not surprising that Back School approach is able to increase the QoL ${ }^{40}$.

In literature has been highlighted that anxiety is an important factor in the fear-avoidance model and how people can postpone their commitments (social, sporting, family-friendly, thus avoiding any activity that can cause pain (e.g., driving, sport) reducing the normal daily functions ${ }^{37}$. Therefore, Yoga, in addition to intervening on the back disuse, may have an antianxiety effect decreasing pain ${ }^{41}$. Furthermore, it has been proven that people, when educating and informing about their disease, improve their psycho-physical conditions ${ }^{42,43}$ also by reducing anxiety and depres- sion $^{44}$. Regarding education, in an interesting review, Louw et al. ${ }^{45}$ have evaluated and confirmed the effectiveness of neuroscience education for pain, disability, anxiety, and stress in chronic musculoskeletal pain.

The Back school treatment is based on education in regard to back. This approach aims to teaching postures to be implemented with respect to daily activities, also providing a broad knowledge about the spine structure and biomechanics, all supplemented by specific exercises useful to correct postures during everyday activities. We hypothesize that Back school may have been decisive in reducing kinesiophobia which in turn, as aformentioned, is influenced and affects the QoL. On the other hand, Yoga is able to improve psychological aspects, even through better awareness and use of breathing.

\section{Conclusion}

Our study is consistent with the literature, but presents both strengths and weaknesses. The main limit of this study can be found in the fact that there was not a real group of control (i.e., it has not carried out any physical program to improve its own CLBP). In this case we could have eventually verified and quantified the effects of a single approach and a combined approach in comparison with no approach. The same thing can be stated for a group of control performing a regular activity with the physiotherapist.

An additional group of control could has been repre- 
Effectiveness of yoga combined with back school program on anxiety, kinesiophobia and pain in people with non-specific chronic low back pain: a prospective randomized trial

sented by subjects informed with a pamphlet reporting a series of exercises to be performed at home thanks to which we could have studied whether they would comply with the exercises or not. However, given a significant difference between the two approaches here studied, this could have been also expected in one of the two supposed groups of control.

A further critical point of this study can be found in the fact that the two groups were followed by the same Yoga trainer while the Y\&B group was followed by a professional in Motor Science.

This group could have benefited from training with two different professionals in addition to the exercises. To the best of our knowledge, our work is the first in the literature to combine two approaches which showed to be useful, taken singularly, to the improvement of CLBP.

The use of the Back School, in particular, could be useful to increase patients' compliance to their course of treatment meant as "taking care of oneself", so much discussed in literature, but then actually little performed: the concept of empowerment.

We think the most important message of our work is not to be searched in the exact combination of the two approaches, but in the necessity to educate the patient who being more aware of his/her pathology, and acquires the tools to become autonomous and protagonist of his/her personal course of treatment (e.g. following the Yoga and Back School exercises at home and being informed about the spinal biomechanics, so he/she can be more aware about the efforts to be done during the daily life). However, we have demonstrated that these two approaches together could have made a difference in improving the psychological aspects we investigated.

\section{Conflict of interest}

The Authors declare that they have no conflict of interest. The results of the study are presented clearly, honestly, and without fabrication, falsification, or inappropriate data manipulation.

\section{References}

1. Vos T, Allen C, Arora M, Barber RM, Bhutta ZA, Brown A, et al Global, regional, and national incidence, prevalence, and years lived with disability for 310 diseases and injuries, 19902015: a systematic analysis for the Global Burden of Disease Study 2015. Lancet. 2016 Oct 8;388(10053):1545-1602.

2. Andersson GB. Epidemiological features of chronic low-back pain. Lancet. 1999 Aug 14;354(9178):581-585.

3. Juniper M, Le TK, Mladsi D. The epidemiology, economic burden, and pharmacological treatment of chronic low back pain in France, Germany, Italy, Spain and the UK: a literaturebased review. Expert Opin Pharmacother. 2009 Nov 30;10(16):2581-2592.

4. National Institute of Neurological Disorders and Stroke. Pain: Hope Through Researchtle [Internet]. Available from: https://www.ninds.nih.gov/Disorders/Patient-Caregiver-Edu-
cation/Hope-Through-Research/Pain-Hope-Through-Research. June 9, 2017.

5. Airaksinen O, Brox Jl, Cedraschi C, Hildebrandt J, Klaber-Moffett J, Kovacs F, et al. Chapter 4. European guidelines for the management of chronic nonspecific low back pain. Eur Spine J. 2006 Mar;15 Suppl 2(S2):S192-300.

6. Currie SR, Wang J. Chronic back pain and major depression in the general Canadian population. Pain. 2004 Jan;107(1-2):5460 .

7. Crown S. Psychological aspects of low back pain. Rheumatology. 1978 May 1;17(2):114-124.

8. Yilmaz Yelvar GD, Çırak Y, Dalkılınç M, Parlak Demir Y, Guner $Z$, Boydak A. Is physiotherapy integrated virtual walking effective on pain, function, and kinesiophobia in patients with nonspecific low-back pain? Randomised controlled trial. Eur Spine J. 2017 Feb 15;26(2):538-545.

9. Kosinski MR, Schein JR, Vallow SM, Ascher S, Harte C, Shikiar R, et al. An observational study of health-related quality of life and pain outcomes in chronic low back pain patients treated with fentanyl transdermal system. Curr Med Res Opin. 2005 Jun 4:21(6):849-862.

10. Åkerström M-L, Grimby-Ekman A, Lundberg M. Work ability is influenced by kinesiophobia among patients with persistent pain. Physiother Theory Pract. 2017 Aug 3;33(8):634-643.

11. Leeuw M, Goossens MEJB, Linton SJ, Crombez G, Boersma K, Vlaeyen JWS. The Fear-Avoidance Model of Musculoskeletal Pain: Current State of Scientific Evidence. J Behav Med. 2007 Jan 31;30(1):77-94.

12. Heymans MW, van Tulder MW, Esmail R, Bombardier C Koes BW. Back schools for nonspecific low back pain: a systematic review within the framework of the Cochrane Collaboration Back Review Group. Spine (Phila Pa 1976). 2005 Oct 1;30(19):2153-2163.

13. Brox JI, Storheim K, Grotle M, Tveito TH, Indahl A, Eriksen HR Systematic review of back schools, brief education, and fearavoidance training for chronic low back pain. Spine J. 2008 Nov;8(6):948-958.

14. Kloubec J. Pilates: how does it work and who needs it? Muscles Ligaments Tendons J. 2011 Apr;1(2):61-66.

15. Kuvacic G, Fratini P, Padulo J, Dello lacono A, De Giorgio A. Effectiveness of yoga and educational intervention on disability, anxiety, depression, and pain in people with CLBP: A randomized controlled trial. Complement Ther Clin Pract. 2018; 31: 262-267 doi: 10.1016/..ctcp.2018.03.008.

16. Saper RB, Lemaster C, Delitto A, Sherman KJ, Herman PM, Sadikova E, et al. Yoga, Physical Therapy, or Education for Chronic Low Back Pain. Ann Intern Med. 2017 Jul 18;167( 2):85.

17. Wieland LS, Skoetz N, Pilkington K, Vempati R, D'Adamo CR, Berman BM. Yoga treatment for chronic non-specific low back pain. In: Wieland LS, editor. Cochrane Database of Systematic Reviews. Chichester, UK: John Wiley \& Sons, Ltd; 2017. p. CD010671.

18. Forssell MZ. The Swedish Back School. Physiotherapy. 1980 Apr:66(4):112-114.

19. van der Hulst M, Vollenbroek-Hutten MMR, ljzerman MJ. A systematic review of sociodemographic, physical, and psychological predictors of multidisciplinary rehabilitation-or, back school treatment outcome in patients with chronic low back pain. Spine (Phila Pa 1976). 2005 Apr 1;30(7):813-825.

20. Padulo J, Oliva F, Frizziero A, Maffulli N. Muscles, Ligaments and Tendons Journal - Basic principles and recommendations in clinical and field science research: 2016 update. MLTJ. 2016;6(1):1-5.

21. Chaouachi A, Padulo J, Kasmi S, Othmen A Ben, Chatra M, Behm DG. Unilateral static and dynamic hamstrings stretching increases contralateral hip flexion range of motion. Clin Physiol Funct Imaging. 2017 Jan;37(1):23-29. 
22. Hamilton $\mathrm{M}$. The assessment of anxiety states by rating. $\mathrm{Br} \mathrm{J}$ Med Psychol. 1959;32(1):50-55.

23. Monticone M, Giorgi I, Baiardi P, Barbieri M, Rocca B, Bonezzi C. Development of the Italian version of the Tampa Scale of Kinesiophobia (TSK-I): cross-cultural adaptation, factor analysis, reliability, and validity. Spine (Phila Pa 1976). 2010 May 20;35(12):1241-1246.

24. Vlaeyen JW, Linton SJ. Fear-avoidance and its consequences in chronic musculoskeletal pain: a state of the art. Pain. 2000 Apr;85(3):317-332.

25. Kori SH, Miller RP, Todd DD. Kinesiophobia: A new view of chronic pain behavior. Pain Manag. 1990;3(1):35-43.

26. Cook AJ, Brawer PA, Vowles KE. The fear-avoidance model of chronic pain: validation and age analysis using structural equation modeling. Pain. 2006 Apr;121(3):195-206.

27. Roland M, Morris R. A study of the natural history of back pain. Part I: development of a reliable and sensitive measure of disability in low-back pain. Spine (Phila Pa 1976). 1983 Mar;8(2): 141-144.

28. Padua R, Padua L, Ceccarelli E, Romanini E, Zanoli G, Bondì $\mathrm{R}$, et al. Italian version of the Roland Disability Questionnaire, specific for low back pain: cross-cultural adaptation and validation. Eur Spine J. 2002 Apr 17;11(2):126-129.

29. Karkoulias K, Lykouras D, Sampsonas F, Karaivazoglou K, Sargianou M, Drakatos $P$, et al. The impact of obstructive sleep apnea syndrome severity on physical performance and mental health. The use of SF-36 questionnaire in sleep apnea. Eur Rev Med Pharmacol Sci. 2013 Feb;17(4):531-536.

30. Cramer H, Lauche R, Langhorst J, Dobos G. Yoga for depression: a systematic review and meta-analysis. Depress Anxiety. 2013 Nov;30(11):1068-1083.

31. Kim SD. Psychological effects of yoga nidra in women with menstrual disorders: A systematic review of randomized controlled trials. Complement Ther Clin Pract. 2017 Aug;28:4-8.

32. Weaver LL, Darragh AR. Systematic Review of Yoga Interventions for Anxiety Reduction Among Children and Adolescents. Am J Occup Ther. 2015 Nov 9;69(6):6906180070p1-9.

33. Vizcaino M, Stover $E$. The effect of yoga practice on glycemic control and other health parameters in Type 2 diabetes mellitus patients: A systematic review and meta-analysis. Complement Ther Med. 2016 Oct;28:57-66.

34. Danhauer SC, Addington EL, Sohl SJ, Chaoul A, Cohen L. Review of yoga therapy during cancer treatment. Support Care Cancer. 2017 Apr 7;25(4):1357-1372.
35. Ribeiro LH, Jennings F, Jones A, Furtado R, Natour J. Effectiveness of a back school program in low back pain. Clin Exp Rheumatol. 26(1):81-88.

36. Borys C, Nodop S, Tutzschke R, Anders C, Scholle HC Strauß B. [Evaluation of the German new back school: pain-related and psychological characteristics]. Schmerz. $2013 \mathrm{Dec}$ 30;27(6):588-596.

37. Pincus T, Smeets RJEM, Simmonds MJ, Sullivan MJL. The fear avoidance model disentangled: improving the clinical utility of the fear avoidance model. Clin J Pain. 2010 Nov;26(9): 739-746.

38. Antunes RS, de Macedo BG, Amaral T da S, Gomes H de A, Pereira LSM, Rocha FL. Pain, kinesiophobia and quality of life in chronic low back pain and depression. Acta Ortop Bras. 2013 Jan;21(1):27-29.

39. Uluğ N, Yakut Y, Alemdaroğlu İ, Yılmaz Ö. Comparison of pain, kinesiophobia and quality of life in patients with low back and neck pain. J Phys Ther Sci. 2016 Jan;28(2):665-670.

40. Morone G, Paolucci T, Alcuri MR, Vulpiani MC, Matano A, Bureca I, et al. Quality of life improved by multidisciplinary back school program in patıents with chronic non-specific low back pain: a single blind randomized controlled trial. Eur J Phys Rehabil Med. 2011 Dec;47(4):533-541.

41. Stubbs B, Koyanagi A, Thompson T, Veronese N, Carvalho AF, Solomi M, et al. The epidemiology of back pain and its relationship with depression, psychosis, anxiety, sleep disturbances, and stress sensitivity: Data from 43 low- and middleincome countries. Gen Hosp Psychiatry. 2016 Nov;43:63-70.

42. De Giorgio A, Dante A, Cavioni V, Padovan AM, Rigonat D, Iseppi $F$, et al. The IARA model as an integrative approach to promote autonomy in COPD patients through improvement of self-efficacy beliefs and illness perception: A mixed-method pilot study. Front Psychol. 2017 Oct 5;8(OCT):1682.

43. De Giorgio A, Loscalzo RM, Ponte M, Padovan AM, Graceffa G, Gulotta F. An innovative mindfulness and educational care approach in an adult patient affected by gastroesophageal reflux: the IARA model. J Complement Integr Med. 2017 May $16 ; 0(0)$.

44. Huang C-Q, Dong B-R, Lu Z-C, Yue J-R, Liu Q-X. Chronic diseases and risk for depression in old age: a meta-analysis of published literature. Ageing Res Rev. 2010;9(2):131-141.

45. Louw A, Zimney K, Puentedura EJ, Diener I. The efficacy of pain neuroscience education on musculoskeletal pain: A systematic review of the literature. Physiother Theory Pract. 2016 Jul 3;32(5):332-355. 